\title{
Division I Athletic Director Trends and Perceptions of Requisite Professional Skills
}

\author{
Eric A. Wood, Ph.D. \\ University of Central Florida \\ Stephen W. Dittmore, Ph.D. \\ University of Arkansas \\ Sarah Stokowski, Ph.D. \\ University of Arkansas
}

Bo Li, Ed.D.

Miami University

\begin{abstract}
The focus of this study was to understand perceptions of National Collegiate Athletic Association (NCAA) Division I athletic director (ADs) skills and experiences and their relative importance to their current position. Division I ADs hold the highest position of authority in intercollegiate athletic departments at the highest level of competition in the NCAA (Swift, 2011). What once was seen as a job for retired coaches has now transformed into a role that attracts some of the top executives both in and outside the sports industry (Belzer, 2015). Indeed, universities have begun to resemble a corporate culture, with ADs frequently considered to be chief executive officers (CEOs) of their department and the universities they serve (Hardin, Cooper, \& Huffman, 2013). Since much of the research on AD career paths has employed a content analysis methodology by examining biographies of ADs to establish patterns, (e.g., Fitzgerald, Sagaria, \& Nelson, 1994; Hardin et al., 2013; Lumpkin, Achen, \& Hyland, 2015), the current study sought to understand ADs' perceptions of requisite skills and experiences by directly surveying the group using an instrument developed for this study. Results indicate that current ADs place a high emphasis on developing skills relative to revenue generation, fundraising, and development, while considering internal experiences such as working with academic services and life skills not nearly as important. Mid-career athletic administrators who aspire to become athletic directors may benefit from the findings.
\end{abstract}

Keywords: athletic director, intercollegiate athletics, executive leadership, career patterns 
The job of a Division I athletic director (AD) has become a much more visible position on college campuses with titles such as "vice chancellor for athletics" increasingly reflecting a corporate structure. Furthermore, the advent of social media has lent a growing celebrity to the role (Dosh, 2013). What once was seen as a job for retired coaches has now transformed into a role that attracts some of the top executives both in and outside the sports industry (Belzer, 2015). Indeed, "[c]ollegiate athletic directors are the chief executive officers within the athletic department and universities they serve" (Hardin et al., 2013, p. 55). Although there is limited academic research regarding AD compensation, Marburger (2015) found that ADs at the Football Bowl Subdivision (FBS) level exhibited a wide range of base salaries, from $\$ 109,293$ to $\$ 1,000,000$. That range falls in line with Brady, Upton, and Berkowitz (2013), who noted the average FBS AD salary was roughly $\$ 515,000$. These coveted CEO positions seem to be appealing career paths for students. Dosh (2013) believes that many students in the current academic climate are entering higher education with the aspirations of becoming an AD. Dosh's beliefs can be affirmed by the sheer amounts of sport management programs that have sprung up since the inaugural sport management program, which was founded at Ohio University in 1966 (Brassie, 1989). According to the North American Society of Sport Management (NASSM), there are nearly 500 institutions of higher learning across the world that offer sport management educational programs (NASSM, 2016). Despite the notion that many students have aspirations of becoming an $\mathrm{AD}$, limited current research exists on the career paths of ADs. Such information could be useful to those students who wish to pursue a career in collegiate sport.

The modern day athletic director job has transformed into a role that attracts some of the top executives both in and outside the sports industry (Belzer, 2015). Though the complexity of the AD's position varies depending on the size and type of institution, the effectiveness of the department is largely determined by the skills and talents of the director and the previous experiences that have prepared him or her for the responsibilities of a directorship (Fitzgerald et al., 1994). Since that 1994 study, additional research has uncovered information about the profile of current collegiate ADs as it relates to education, age, race, and gender.

Each of the 350-plus schools that currently make up Division I member institutions has a full-time $\mathrm{AD}$ responsible for the oversight of the organization within a higher education setting. According to Marburger (2015), the AD "must wear a number of hats with both internal and external responsibilities" (p. 255). The roles ADs play vary from hiring decisions, budget oversight, supervision, compliance (with institutional/conference/NCAA regulation), as well as fundraising efforts (Marburger, 2015). In other words, this position requires a professional who can put the athletic department in a financial position that would reduce the need to tap into already strained university budgets.

Over the past 30 years, the competitive landscape of colleges and universities, and more specifically athletic departments within them, has changed dramatically due to governmental legislation and a number of economic factors that have increased the exposure and visibility of NCAA Division I schools (Fram \& Frampton, 2012). These factors include everything from compliance violations, Title IX legislation, academic eligibility, drug testing, increasing television revenues, and anti-trust legislation (Hatfield, Wrenn, \& Bretting, 1987). More recently, studentathletes' attempts at unionization, NCAA image and likeness legislation, multiyear athletic scholarships, proposals for pay-for-play, cost of attendance, as well as the formation of the College 
Football Playoff system has molded the current culture within collegiate sport (Gruna, 2017; Salaga \& Fort, 2017).

Historically, many ADs were former celebrated head football coaches, appointed to the AD position as a gesture of respect for years of service and commitment to their respective colleges/universities (Duderstadt, 2003). Though the complexity of the AD's position varies depending on the size and type of institution, the effectiveness of the department is largely determined by the skills and talents of the director and the previous experiences that have prepared him or her for the responsibilities of a directorship (Fitzgerald et al., 1994).

Academic studies of $\mathrm{AD}$ profiles, responsibilities, and career paths are numerous (Fitzgerald et al., 1994; Hardin et al., 2013; Hatfield et al., 1987; Lumpkin et al., 2015; Quarterman, 1992; Smith \& Washington, 2014; Taylor \& Wells, 2017). Hardin et al. (2013) examined the daily responsibilities of Division I ADs. Belzer (2015) revealed that the skill sets needed to be a successful AD varied due to the division and the budget of the athletic department. However, limited research exists regarding specific attributes that ADs view as important to their position. Furthermore, there is a gap in the literature regarding how ADs differ based on their affiliation (e.g., FBS, Football Championship Subdivision [FCS], Division I-no football). Unfortunately, the majority of studies that examine this population do not survey the population of Division I ADs directly, instead relying on content analysis of biographies to make inferences about the requisite skills and experiences necessary for a successful Division I AD in today's college athletic environment.

The purpose of the present study, therefore, is to add to this body of literature on ADs by directly reporting the perceptions of sitting ADs. The present study utilizes quantitative methodology, surveying Division I ADs directly, instead of relying on content analysis of AD biographies to make inferences about the requisite skills and experiences necessary for a successful Division I AD in the current college athletic environment. This research may be beneficial to aspiring and entry-level collegiate athletics administrators, as the landscape of college athletics has changed significantly since Fitzgerald et al. (1994) identified a "normative" path for college ADs. They found that the most common shared experience among ADs was their roles as former student-athletes (80\%). Sixty-five percent of sitting ADs in 1994 were involved in collegiate coaching immediately before securing the top spot. Fitzgerald et al. (1994) identified a five-step normative pattern that included: collegiate athlete, high school coach, college coach, assistant/associate $\mathrm{AD}$, and $\mathrm{AD}$. Though most of the incumbent ADs did not hold all five positions in the proposed sequence, an examination of the chronological order of positions illustrated that 189 out of the 200 respondents (94.5\%) experienced the linear time sequence of the normative career patterns.

Empirical studies since that foundational study suggest that the normative model no longer exists, and that $\mathrm{ADs}$ need more experiences in business and management than the mere qualification of serving as an athlete and coach (Lumpkin et al., 2015). Yet, the fact remains that few, if any, studies have asked sitting ADs at the Division I level directly about their backgrounds and relevant experiences. Therefore, the researchers developed two primary questions to address this literature gap: 
RQ1: What are the professional and educational trends most common among contemporary NCAA Division I ADs?

RQ2: What skills and experiences do NCAA Division I ADs perceive to be the most important to be effective in their jobs? Do these vary by Division I sub-group?

\section{Review of Literature}

As a result of the changing landscape in Division I athletics, there is a need to understand what skills and experiences the modern day Division I collegiate AD possesses compared to the ADs who were the focus of empirical studies more than two decades ago. Few studies provide a practical approach on the specific career paths of ADs at the Division I level.

\section{Profile of Athletic Directors}

Numerous scholars have attempted to create a profile of the college AD. One of the earliest attempts to do so was by Hatfield et al. (1987), who compared ADs to general managers of professional sport organizations. Data from this study revealed that the most popular undergraduate major for ADs was physical education while most general managers chose business, prompting the researchers to suggest that the educational backgrounds of the two populations reflect their professional environments: one education-focused, the other business-focused, respectively. Hatfield et al. (1987) were among the first to propose the idea that experience as a former student-athlete and coach prepared ADs for their administrative roles. ADs responded positively (87.7\%) about the importance of being an athlete, while general managers were mixed, with only 55\% replying affirmatively. Coaching experience was a significant contributing factor to present effectiveness; approximately $80 \%$ of the ADs believed coaching was beneficial, while only $40 \%$ of the general managers responded affirmatively. The authors suggested that perhaps previous coaching experience increased their sensitivity to those demands placed upon the coaches and athletes within their programs (Hatfield et al., 1987).

Quarterman (1992) sought to create a profile of ADs at Historically Black Colleges and Universities (HBCUs) by comparing data collected with that of ADs at Predominantly White Institutions (PWIs). The author found that the average age of responding ADs was 46.1 years of age, with nearly a decade (9.5 years) as athletic administrators. Most (62.2\%) held a master's degree as their highest degree, but $29.3 \%$ held a doctorate. Undergraduate degrees in health and/or physical education were held by $69 \%$ of the ADs and half (50.4\%) held graduate degrees in health and/or physical education. The majority $(84.4 \%)$ of the respondents had teaching experience and nearly all (89\%) had coaching experience. In fact, over one-third (36.3\%) of the respondents were assigned coaching responsibilities when the survey was conducted, with $71 \%$ coaching basketball.

In the aforementioned Fitzgerald et al. (1994) study, the researchers found that the average age of responding ADs was 48.7 years, with $85 \%$ having earned a master's degree, while $21.5 \%$ had completed a doctorate. The most common experiences on the five rungs (college athlete, high school coach, college coach, assistant or associate athletic director, and athletic director) were as a collegiate athlete $(80 \%)$ or collegiate coach $(65 \%)$. Though most of the respondents did not hold all five positions, an examination of the chronological order of positions held illuminated that 
94.5\% had followed the linear time sequence of the positions in the normative career pattern experience. The authors also found that while career patterns of ADs do suggest collegiate athlete participation as a portal of entry, collegiate coaching was the most common antecedent professional position for the $\mathrm{AD}$ position.

More recently, Smith and Washington (2014) suggested that organizations tend to model themselves after other organizations within their field that are perceived to be more successful. The authors' core argument proposes that the collective acquisition of formal education and work experience is similar across all ADs, regardless of the school they are leading. As a result, this creates mimicking or isomorphic properties in college athletics. The transition from the autocratic, coaching-centered $\mathrm{AD}$ to one that has a strong business background with emphasis in fundraising and marketing has yet to be widespread throughout the NCAA, but it is becoming clear that ADs have followed a clear progression of career experiences (Smith \& Washington, 2014).

Wong, Deubert, and Hayek (2015) updated the work of Fitzgerald et al. (1994), suggesting that four tracks account for the majority of career paths of Division I ADs between 1989-90 and 2013-14. The four tracks are categorized as: collegiate playing, collegiate coaching, business, and academia. Their findings emphasized, "less coaching experience and more business experience" (p. 73) as the primary trends, owning to the increased importance in revenues associated with Division I FBS athletic programs.

Lumpkin et al. (2015) compared profiles of Division I ADs with those of other NCAA divisions, finding underrepresentation of females in all division, but particularly in Division I. The study recommended that aspiring students should focus on obtaining an advanced degree, particularly in fields such as sport management, communication, business management, and law. Furthermore, their findings revealed only $31.2 \%$ of Division I ADs had experience as a coach, as compared to 69\% in Division II and 75.6\% in Division III.

Taylor and Wells' (2017) qualitative study identified institutional barriers and support that female ADs experienced at NCAA Division I institutions. Most of the women disclosed that they had been seasoned coaches and athletic administrators prior to being encouraged to pursue an AD position by individuals in power (males). Although the women noted the need to diversify hiring practices, the participants felt there was a "shift" regarding the "good old boys" network that was often perceived to control intercollegiate sport (Taylor \& Wells, 2017, p. 170).

Dittmore et al. (2011) found that $85 \%$ of FBS ADs held assistant or associate athletic director positions prior to taking the chief position, a 45\% increase from Fitzgerald et al.'s (1994) findings. Dittmore et al. (2011) attributed a shift in the career paths of ADs to the growth in degree programs specifically tailored to training students to work in sports, including programs geared towards college athletics. As Dosh (2013) noted, "Today, students go to college with the goal of becoming an $\mathrm{AD}$, a reality that largely wasn't true thirty years ago" (p. 105).

Dosh (2013) reported that although several recent AD hires came from outside the world of collegiate athletics, the perception that universities are moving to corporate America to fill the roles and manage multimillion dollar budgets is deceiving. In 2011, only 15 FBS ADs did not hold a position within a college athletic department immediately prior to their appointment as AD 
(Dittmore et al., 2011). Dosh (2013) concludes the role of the AD as specialized and requires working knowledge of different areas within collegiate athletics from compliance to development to communication and more. While a master's degree in business or a law degree adds depth of knowledge, it takes more than a degree or a few years working at a Fortune 500 company to have the knowledge and connections necessary to lead a collegiate athletic department.

\section{Role of the Athletic Director}

Athletic department positions are frequently categorized as either external or internal, based on how the position interacts with organizational stakeholders. External positions, such as marketing, development, ticket sales, and media relations emphasize skills related to glad-handing, fundraising, negotiating, strategic communication, sponsorships, and administrative skills required of modern day ADs (Suggs, 2005). Internal positions such as compliance, business operations, academics, life skills, and facility management were not considered peripheral jobs, meaning an administrator could become an assistant or associate athletic director, but making the jump to the AD position was very difficult (Suggs, 2005).

Taylor and Wells' (2017) study found that gender could impact AD roles. Females are often perceived as neutering; as such, female ADs are often restricted to more internal responsibilities not only within the athletic department, but also within the realm of the university (Taylor \& Wells, 2017). Furthermore, female ADs reported having a difficult time adjusting to external responsibilities, such as having to play golf with male donors in order to fundraise due to the gender normative behavior often elevated through sport (Taylor \& Wells, 2017).

This external position focus is evident in Spenard's (2011) research on Division I AD weekly involvement in specific departments and operations. The study revealed the top three core areas in which ADs were primarily involved each week: (a) allocating financials and budgetary oversight, (b) internal policy-making, and (c) fundraising. The 99 ADs in Spenard's (2011) sample also reported little to no weekly involvement in facilities, equipment, and recruiting.

Hardin et al. (2013) found that while $80 \%$ of participating ADs cited student-athlete success and development as the most rewarding aspect of the position, their top priorities were budgets, financials, marketing, and fundraising. The authors suggested that the days of the athletic directorship being based on mentoring student-athletes and sports management are long gone. The position has evolved; rarely do ADs interact directly with student-athletes or even staff members on a regular basis due to increasing CEO and business-oriented functions. The focus of the AD tends to shift to revenue generation in order to continually provide resources and facilities for student-athletes and coaches to remain competitive nationally, which forces many to take on the roles they feel are most important or essential and subsequently delegate additional tasks to others.

Belzer (2015) was more explicit in his explanation of AD job duties, even categorizing perceived responsibilities across NCAA subgroups. He suggested that managing the athletic department of a major university is similar to running a major corporation. Specifically, he noted the qualifications necessary for ADs in FBS Autonomy schools, members of the Southeastern, Atlantic Coast, Big Ten, Big-12, and Pac-12 conferences, which voted in 2014 to allow members to provide more resources to athletes (Solomon, 2014), included: negotiating multi-million-dollar 
media rights; managing powerful head coaches who are often the highest paid employees in the state; and possessing advanced knowledge of strategic, operational, and financial business planning. Belzer noted the importance of ADs having a high understanding of business operations and concluded that there is no single correct answer to identifying the skill sets of the great ADs, but that it is important to understand the key challenges ADs face at each level of the industry as one moves forward in his or her career.

Belzer's (2015) work mirrors that of Wong et al. (2015), who categorized the duties of a Division I AD. These categories included: NCAA issues and compliance; conference issues and responsibilities; university rules, regulations, and responsibilities; compliance with Title IX; and negotiating contracts. The focus of Wong et al. underscores the importance of a legal background for athletic directors, using individual case studies to illustrate these duties. Curiously absent in Wong et al.'s work is the duty of fundraising and revenue generation, despite the authors' assertion that "athletic directors' duties are closely tied to generating and protecting" (pp. 11-12) revenues.

The present study extends the work of Hardin et al. (2013), Wong et al. (2015), and Belzer (2015) by focusing on skills and experiences that ADs believe have been helpful in their career progressions, while pointing out differences among Division I AD subgroups. All of the previous studies emphasized the tasks an AD must complete in their role, but none provided guidance to aspiring ADs. In the past, AD positions were reserved for former celebrated head football coaches as a sign of respect. The research suggests that experiences as a coach and/or a student-athlete are beneficial to an $\mathrm{AD}$ position, but the landscape of college athletics has changed over the last 30 years. Thus, the experiences and skills required for the position reflect this shifting dynamic.

\section{Athletic Director as CEO}

With their involvement in fundraising, negotiating multimillion-dollar deals, managing powerful head coaches, and financial planning as the top qualifications, the role of modern day collegiate athletic directors more accurately resembles that of a corporate chief executive officer. Due to the changing nature of athletic departments, university presidents are looking to hire candidates with a range of skills and experiences, since they are responsible for self-supporting entertainment businesses while maintaining acceptable academic values (Duderstadt, 2003). Business professors Piercy and Forbes (1991) suggested that the path an executive takes and their functional expertise, or skill set, in the business world can impact their upward mobility.

Upward mobility potential was measured by level of education, breadth of experience, entry through prestigious training programs, work experience at a powerful department, early service as assistant to a senior manager, and acquisition of a functional background closely related to the critical problems facing the corporation. The middle years, after appointment as general manager or functional vice president, were not only based on the bottom line performance but also "soft" issues such as values and team chemistry. Finally, selection for chief executive officer involved record of accomplishment as well as evidence that the person was needed at that particular time (Piercy \& Forbes, 1991).

Favaro, Karlsson, and Neilson (2010) conducted a 10-year analysis of detailed data on chief executive officer succession planning among the world's top 2,500 companies. Two themes 
that emerged were convergence and compression. Convergence meant there was harmonization of chief executive officer turnover rates across the world and in every industry. The 10-year turnover averages were between 12 and 14 percent for corporate chief executive officers. This statistic was in line with the 10-year turnover averages for athletic directors, also 12\% (Hardin et al., 2013). Compression is the second theme that emerged from the 10-year analysis of corporate chief executive officers, meaning the executives had more to prove in less time. Overall, the tenure of the chief executive officer is becoming shorter and more intense with narrow margins for error or underperformance (Favaro et al., 2010).

\section{Method}

The purpose of this study was to understand NCAA Division I AD perceptions of the skills and experiences necessary to be an effective AD. The survey sought to identify how important skills and experiences were to ADs in 19 different daily administrative tasks. Specifically, the following research questions were addressed:

RQ1: What are the professional and educational trends most common among contemporary NCAA Division I ADs?

RQ2: What skills and experiences do NCAA Division I ADs perceive to be the most important to be effective in their jobs? Do these vary by Division I sub-group?

\section{Survey Development}

In order to create the survey instrument, 19 daily administrative tasks were identified based on the job experience of the primary researcher, who serves as a Senior Associate Athletic Director in academic support at an FBS institution and has 18 years of intercollegiate athletic administration experience. The identified tasks emerged as a result of the primary researcher's background as well as conversations with other athletic administrators.

To ensure face validity, five additional NCAA senior associate level ADs who represented NCAA Division I member institutions reviewed and edited the survey to ensure items reflected the content domain. Each expert received an email, which included the purpose of the study, an explanation of the procedures, and a set of items to review and rate how relevant they thought each of the items were to what the author intended to measure. The experts provided feedback regarding the potential omission of items, definitions of items, and latent variables. Individual items were measured on a 7-point Likert-type scale with anchors of Not At All Important (1) and Very Important (7). Additionally, the survey contained demographic questions as well as open-ended questions seeking to assess the AD's career path.

\section{Participants}

Upon receiving approval from the Institutional Review Board (IRB), email addresses from 350 Division I ADs were pulled from membership directories and sent a survey link to a Google Forms document. Participation in the study was voluntary and information regarding the participants' rights were included in the email. Using Dillman's (2000) total design method as a 
guide, a reminder email was sent to all participants two weeks after the original e-mail was sent to increase survey responses. SPSS 22.0 was used to calculate descriptive statistics along with ANOVA tests to examine differences in perceptions by subgroup.

\section{Results}

About one-third $(N=116)$ usable responses were received from the population for a final response rate of $33.1 \%$. Among all participants, most of the ADs $(n=48,43.6 \%)$ identified as FCS, with the second highest representation classified as I-AAA $(n=27,24.5 \%)$ and the third largest group of participants classified themselves as FBS $(n=22,20 \%)$. The smallest subgroup was FBS Autonomy $(\mathrm{n}=19,17.3 \%)$. As a general statement, FCS had the highest participation in the final study sample with $38.4 \%$ of FCS schools participating. FBS was second with $34.9 \%$ of schools participating, followed by FBS Autonomy with $29.2 \%$ of schools participating. I-AAA was the least represented of the Division I subgroups with $27.6 \%$ of schools participating. 


\section{Research Question 1}

The first research question (RQ1) asked which professional and educational trends are most common among contemporary NCAA Division I ADs. The average age of the participants was 51.2 years $(S D=10.15)$, with a range of 29-70. The majority of the participants were male $(\mathrm{n}=103,88.7 \%)$ and white $(\mathrm{n}=98,84.5 \%)$, with an average of 22.8 years of work experience $(S D=9.14)$ ranging from 5.5-46 years. As it related to educational levels, the majority of the participants selected a master's degree as the highest degree earned $(n=82,70.69 \%)$ with the top five academic majors in Sports Management $(n=31)$, Business $(n=30)$, Physical Education $(n=16)$, Communications/Journalism $(n=12)$, and Education $(n=12)$. Seventy-six $(65.5 \%)$ participants identified as former NCAA studentathletes but only $46(39.7 \%)$ had NCAA coaching experience. The participants who identified as former student-athletes believed their athletics experience in college was very important to their current job as $\mathrm{AD}(M=5.8, S D=1.55)$. The participants with coaching experience also believed their time coaching was very important in their role as $\mathrm{AD}(M=5.9, S D=1.82)$. Full descriptive statistics, including subgroup percentages, are presented in Table 1.

Table 1

Personal and Professional Characteristics of Division I Athletic Directors by Classification

\begin{tabular}{cccccc}
\hline & FBS Autonomy & FBS & FCS & I-AAA & Overall \\
\hline Male & 19 & 20 & 41 & 23 & $103(88.8 \%)$ \\
Female & 1 & 2 & 6 & 4 & $13(11.2 \%)$ \\
White & 15 & 20 & 41 & 22 & $98(84.5 \%)$ \\
Black & 3 & 2 & 5 & 4 & $14(12.1 \%)$ \\
Hispanic & 0 & 0 & 2 & 1 & $3(2.5 \%)$ \\
American Indian & 1 & 0 & 31 & 0 & $1(0.9 \%)$ \\
Student-Athlete & 13 & 17 & 19 & 9 & $75(63 \%)$ \\
Coach & 8 & 10 & $53.4(S D=9.79)$ & $50.09(S D=10.23)$ & $49.73(S D=10.72)$ \\
Age & $53.7(S D=9.07)$ & $53.4(38.6 \%)$ & \\
\hline
\end{tabular}




\section{Research Question 2}

Research Question 2 focused on the skills and experiences NCAA Division I ADs perceived to be the most important to be effective in their jobs. The top three overall skills and experiences NCAA Division I ADs perceived as most important to be effective were fundraising $(M=5.92, S D=1.31)$, sport oversight $(M=5.86, S D=1.40)$ and development $(M=5.68, S D=1.27)$. Table 2 depicts means and standard deviations for all items, as well as classification by subgroup.

Table 2

Means and Standard Deviations of the Perceptions of the Level of Importance of Skills and Experiences of ADs by NCAA Division I Classification Subgroup

\begin{tabular}{|c|c|c|c|c|c|c|c|c|c|c|}
\hline \multirow[t]{2}{*}{ Skills/ Experiences } & \multicolumn{2}{|c|}{$\begin{array}{l}\text { FBS Autonomy } \\
(n=19)\end{array}$} & \multicolumn{2}{|c|}{$\begin{array}{c}\text { FBS } \\
(n=22)\end{array}$} & \multicolumn{2}{|c|}{$\begin{array}{c}\text { FCS } \\
(n=48)\end{array}$} & \multicolumn{2}{|c|}{$\begin{array}{l}\text { I-AAA } \\
(n=27)\end{array}$} & \multicolumn{2}{|c|}{$\begin{array}{l}\text { Overall } \\
(N=116)\end{array}$} \\
\hline & $M$ & $S D$ & $M$ & $S D$ & $M$ & $S D$ & $M$ & $S D$ & $M$ & $S D$ \\
\hline Fundraising & 5.58 & 1.54 & 6.36 & 1.09 & 5.98 & 1.19 & 5.70 & 1.49 & 5.92 & 1.31 \\
\hline Sport Oversight & 5.32 & 1.89 & 6.41 & 1.01 & 6.00 & 1.29 & 5.56 & 1.31 & 5.86 & 1.40 \\
\hline Development & 5.42 & 1.30 & 6.00 & 1.15 & 5.71 & 1.29 & 5.56 & 1.31 & 5.68 & 1.27 \\
\hline Strategic Planning & 5.47 & 1.35 & 5.64 & 1.50 & 5.77 & 1.37 & 5.59 & 1.34 & 5.66 & 1.37 \\
\hline Crisis Communications & 5.58 & 1.12 & 5.95 & 1.74 & 5.67 & 1.28 & 5.41 & 1.55 & 5.65 & 1.30 \\
\hline Handling HR Issues & 5.05 & 1.27 & 5.68 & 1.36 & 5.81 & 1.36 & 5.52 & 1.42 & 5.59 & 1.37 \\
\hline Comm. Training & 5.42 & 1.57 & 5.36 & 1.22 & 5.67 & 1.43 & 5.22 & 1.55 & 5.47 & 1.44 \\
\hline Contract Negotiations & 5.42 & 1.30 & 5.86 & 1.21 & 5.45 & 1.43 & 5.11 & 1.63 & 5.44 & 1.42 \\
\hline Capital Projects & 5.16 & 1.42 & 6.00 & 1.15 & 5.43 & 1.22 & 5.19 & 1.59 & 5.44 & 1.35 \\
\hline Business Operations & 4.89 & 1.24 & 5.50 & 1.34 & 5.25 & 1.44 & 4.81 & 1.75 & 5.14 & 1.47 \\
\hline
\end{tabular}




\section{Volume 1, Issue 5}

\begin{tabular}{|l|c|c|c|c|c|c|c|c|c|c|}
\hline Compliance & 4.63 & 1.30 & 5.63 & 1.50 & 5.17 & 1.40 & 4.56 & 1.22 & 5.03 & 1.40 \\
\hline Marketing & 4.74 & 0.99 & 5.13 & 1.28 & 4.66 & 1.31 & 4.22 & 1.40 & 4.66 & 1.30 \\
\hline Media Relations & 4.63 & 1.38 & 5.09 & 1.54 & 4.69 & 1.42 & 4.03 & 1.51 & 4.60 & 1.48 \\
\hline Sponsor Solicitation & 4.11 & 1.37 & 4.55 & 1.50 & 4.71 & 1.47 & 4.37 & 1.39 & 4.50 & 1.44 \\
\hline Sport Performance & 4.11 & 1.52 & 4.86 & 1.96 & 4.00 & 1.29 & 3.96 & 1.63 & 4.17 & 1.57 \\
Event Management & 4.00 & 1.41 & 4.82 & 1.53 & 4.06 & 1.12 & 3.93 & 1.52 & 4.16 & 1.37 \\
Academic Services & 3.95 & 1.18 & 4.77 & 1.60 & 4.17 & 1.23 & 3.52 & 1.25 & 4.09 & 1.35 \\
Facilities Management & 3.94 & 1.35 & 4.77 & 1.63 & 3.96 & 1.18 & 3.67 & 1.49 & 4.04 & 1.14 \\
Life Skills Programming & 3.79 & 1.23 & 4.18 & 1.62 & 3.68 & 1.21 & 3.33 & 1.24 & 3.75 & 1.32
\end{tabular}


To further examine this RQ2, a series of ANOVA tests using Division I classification (i.e., FBS Autonomy, FBS, FCS, and I-AAA) as a grouping variable were run to see if there were differences between the four groups. The results of a one-way ANOVA revealed the difference in the perception of the level of importance of sport oversight among ADs in FBS Autonomy ( $n=19$, $M=5.32, S D=1.89)$, FBS $(n=22, M=6.41, S D=1.01)$, FCS $(n=48, M=6, S D=1.29)$, and I-AAA $(n=27, M=5.55, S D=1.31)$ were statistically significant, $F(3,112)=2.82, p=.04$. Post hoc least significant difference (LSD) tests showed that ADs in FBS autonomy viewed sport oversight as significantly less important than ADs in FBS, $t=-1.09, p=.12$. Meanwhile, ADs in FBS viewed sport oversight statistically more important than ADs in I-AAA, $t=-.85, p=.031$. There was also a statistically significant difference in the perception of the level of importance of compliance among ADs in FBS autonomy $(n=19, M=4.63, S D=1.3)$, FBS $(n=22,5.64, S D=1.50)$, FCS $(n=48$, $M=5.17, S D=1.40)$, and I-AAA $(n=27, M=4.56, S D=1.22)$ as determined by ane-way ANOVA, $F(3,112)=3.23, p<.05$. A post hoc LSD test showed that ADs in FBS autonomy viewed compliance as statistically significantly less important than ADs in FBS, $t=-1.00, p=.021$. Meanwhile, ADs in FBS view compliance as statistically more important than ADs in I-AA, $t=1.08, p=.01$.

A one-way ANOVA revealed there were significant differences in academic services among ADs in FBS autonomy $(n=19, M=3.94, S D=1.18)$, FBS $(n=22, M=4.77, \mathrm{SD}=1.60)$, FCS $(n=48, M=4.17, S D=1.23)$, and I-AAA $(n=27, M=3.51, S D=1.25), F(3,112)=3.87, p=.01$. After conducting post hoc LSD tests, the results suggested that ADs in FBS valued academic services statistically significantly higher than ADs in FBS autonomy conferences, $t=.83, p=.046$. Meanwhile, ADs in FBS viewed academic services significantly more important than ADs in IAAA, $t=1.25, p=.001$. Also, FBS ADs perceived academic services skills as more important than I-AAA ADs, $t=.65, p=.041$. Facilities management was the final skill that was found to be statistically significant amongst ADs in FBS autonomy $(n=19, M=3.94, S D=1.35)$, FBS $(n=22$, $M=4.77, S D=1.63)$, FCS ( $n=48, M=3.96, S D=1.18)$, and I-AAA ( $n=27, M=3.67, S D=1.49)$, after conducting an ANOVA test, $F(3,112)=2.81, p=.04$. After conducting post hoc LSD tests, the results suggested that ADs in FBS viewed facilities management significantly more important than their counterparts at FCS institutions, $t=.81, p=.024$, and ADs in I-AAA, $t=1.11, p=.006$. 
Table 3

ANOVA Summary Table for Subgroup x Athletic Director Skills and Experiences

\begin{tabular}{clrll}
\hline & MS & \multicolumn{1}{l}{ SS } & \multicolumn{1}{l}{$\boldsymbol{F}$} & \multicolumn{1}{l}{$\boldsymbol{p}$} \\
\hline Fundraising & 2.657 & 7.970 & 1.547 & .206 \\
Sport Oversight & 5.234 & 15.703 & 2.817 & .042 \\
Development & 1.328 & 3.983 & 0.821 & .485 \\
Strategic Planning & 0.460 & 1.381 & 0.240 & .868 \\
Crisis Comm. & 1.246 & 3.737 & 0.731 & .535 \\
Handling HR Issues & 2.728 & 8.184 & 1.470 & .226 \\
Comm. Training & 1.269 & 3.806 & 0.605 & .613 \\
Contract Neg. & 2.292 & 6.876 & 1.138 & .337 \\
Capital Projects & 3.388 & 10.165 & 1.894 & .135 \\
Business Operations & 2.477 & 7.430 & 1.144 & .334 \\
Compliance & 6.026 & 18.077 & 3.231 & .025 \\
Marketing & 3.426 & 10.279 & 2.095 & .105 \\
Media Relations & 4.748 & 14.244 & 2.239 & .088 \\
Sponsor Solicitation & 1.848 & 5.543 & 0.886 & .451 \\
Sport Performance & 4.403 & 13.208 & 1.831 & .146 \\
Event Management & 3.984 & 11.951 & 2.188 & .093 \\
Academic Services & 6.579 & 19.738 & 3.874 & .011 \\
Facilities Mgmt & 5.352 & 16.057 & 2.818 & .042 \\
Life Skills Prog. & 2.956 & 8.869 & 1.736 & .164 \\
\hline & & & & \\
\hline
\end{tabular}

Note. Each variable has $\mathrm{df}=3$. Error $\mathrm{df}=112$ for both variables; $* p<.05$ 


\section{Discussion}

Results of the present study helped to paint a clearer profile of current Division I ADs, from a description of the individual to the experiences that influenced the AD's ascension to his or her current position. On average, a Division I AD in 2016 was a 51-year-old white male with more than 20 years of experience, a master's degree, and undergraduate majors in sport management (31), business (30), or physical education (16). Nearly two-thirds (65\%) of sitting $\mathrm{AD}$ participants were former NCAA student-athletes, while approximately $40 \%$ were NCAA coaches.

This current profile suggests an evolving level of importance of formal education for today's AD relative to previous examinations of the profession. When compared with the sample in Fitzgerald et al.'s (1994) study more than two decades ago, 15\% percent fewer (70.7\% compared to $85 \%$ ) of the ADs hold a master's degree as the highest degree earned, and $8 \%$ percent fewer (13.8\% to $21.5 \%$ ) hold a doctorate. Furthermore, more than half of the participants $(52.5 \%)$ in the present study had majored in sport management or business, compared to the high percentage of physical education majors found in Hatfield et al. (1987), which was 71.9\%, and Quarterman (1992), which was 69\%. This finding suggests a shift toward business-related skills necessary to be an $\mathrm{AD}$. Given the trend toward fiscal responsibility and revenue generation in Division I athletics (Hardin et al., 2013), it is not surprising that present ADs need more training in businessrelated fields. Furthermore, the emergence of sport management as an appropriate academic major is attributable to the growth of sport management degree programs from the mid-1990s to today (Jones, Brooks, \& Mak, 2008). That many ADs chose this major suggests that sport management degree programs are providing aspiring athletic administrators with the appropriate skills and curriculum to become successful administrators.

Approximately two-thirds (65\%) of current ADs identified themselves as former NCAA student-athletes, as compared to 80\% in Fitzgerald et al.'s (1994) foundational study. Furthermore, only $39.7 \%$ indicated they had NCAA coaching experience as compared to $65 \%$ in 1994, which was in line with Lumpkin et al. (2015), who observed that $32.2 \%$ of Division I ADs had coaching experience. While the number of ADs who were former NCAA student-athletes and/or former NCAA coaches has decreased substantially over the last 20 years, the ADs participating in the present study believed that their past student-athlete $(M=5.8, S D=1.6)$ and coaching experiences $(M=5.9, S D=1.8)$ were important in aiding their current roles.

When asked to identify how important an individual experience or skill was to their current role, ADs in the present study ranked fundraising, sport oversight, and development as the most important areas of focus. For the purpose of the current study, fundraising was considered a managerial task, while development was considered a functional task. Future studies may wish to collapse these two tasks into one item. Each subgroup of ADs (i.e., FBS Autonomy, FBS, FCS, IAAA) had fundraising ranked first or second in terms of level of importance to be effective in their current jobs (see Table 3). Previous research has suggested that the AD's role has changed in the past 20 years (Dosh, 2013; Hardin et al., 2013; Spenard, 2011). The number of assistant/associate ADs doubled from approximately $40 \%$ to $85 \%$ between 1994-2011 as these individuals gained first-hand experience in fundraising, negotiating multi-million dollar deals, and financial planning (Dosh, 2013). 
While each subgroup ranked fundraising as either the first or second most important skill, the Autonomy AD subgroup also ranked crisis communications as tied with fundraising $(M=5.58)$ for most important. No other subgroup ranked crisis communications higher than fifth. This finding may shed light on the actual job duties of an AD at an FBS Autonomy institution. Scandals increasingly plague college athletics, with most of the attention falling to prominent institutions such as the University of North Carolina-Chapel Hill, Baylor University, and Penn State University. As the media devote time and attention to these scandals, it seems ADs need to have formalized experience in managing organizational messaging and communicating with members of the media, as well as outside stakeholder groups. Fewer ADs reported an academic background in communications or journalism than in business, education, and sport management, begging the question of where ADs acquire the appropriate skills and strategies for managing crises.

In evaluating individual mean differences among the four classifications (i.e., sport oversight, compliance, academic services, and facilities management), ADs differed dramatically on the perceived level of importance. FBS Autonomy ADs scored lower on the perceived importance of all four of these experiences than their FBS, FCS, or I-AAA counterparts. Emphasis on revenue generation for FBS Autonomy schools may force ADs to focus on those skills and delegate responsibility of internal tasks, such as sport oversight and compliance, to assistant or associate directors.

Particularly interesting to note was the low mean score of FBS Autonomy ADs ( $M=3.94)$ and I-AAA ADs $(M=3.52)$ on academic services, as opposed to their FBS $(M=4.77)$ and FCS colleagues $(M=4.17)$. The NCAA, as well as ADs, frequently mention the education of studentathletes as critical to their jobs, but this low score of perceived importance suggests the ADs themselves are not involved in academic policies. Overall, the ADs ranked Life Skills Programming last in terms of importance $(M=3.75)$ with Academic Services $(M=4.09)$ third-tothe-bottom. That Life Skills Programming and Academic Services, both related to the holistic wellbeing of student-athletes, are ranked so low on the totem pole is worrisome. It may suggest that the narrative about ADs caring for student-athlete experiences is just rhetoric, and that, in reality, ADs are more concerned with external pieces of the department.

It is worth noting that participants in the present study were not necessarily representative of the overall population of NCAA Division I ADs. Nineteen of the participants were affiliated with FBS Autonomy schools, $29 \%$ of the overall population of 65 autonomy schools. Universities in this group, known colloquially as the Power 5 Conferences, tend to have the highest revenues, often in excess of $\$ 100$ million per year.

Twenty-two of the participants were affiliated with the FBS Group of 5 schools, often referred to as mid-major schools. The overall number of Group of 5 schools is changing each year as schools reclassify, with a current population of 63 schools. These schools tend to have revenues between \$30-50 million each year. All schools in the FBS Autonomy group and the FBS Group of 5 have similar requirements for sports sponsorship and scholarships. 
Nearly two-thirds of the study participants (64.7\%) came from FCS and I-AAA schools. These universities compete at the Division I level, but do not fund as many scholarships. As such, their revenues and expenses tend to be less than $\$ 25$ million. Comparisons across these four groups should be made with caution and context. Future research may seek to tease out nuances among these groups.

\section{Implications}

Previously, many studies relied on content analysis of athletic department websites and the collection of $\mathrm{AD}$ résumés to make assumptions about what it takes to become an effective Division I AD. This study contributes new information to the industry by focusing on perceptions of the skills and experiences needed to be effective Division I ADs directly from sitting ADs. Aspiring ADs should know that on average, it will take about 23 years of experience to become a Division I AD. Most of the ADs have a master's degree and have majored in Sports Management, Business, or Physical Education. While the numbers of sitting Division I ADs who are former NCAA student-athletes and/or coaches has decreased from 20 years ago, those experiences have proven to be valuable to them in their leadership of young people and coaches today.

Aspiring ADs of color need to be aware of the fact that 90\% of sitting ADs in 2011 were white, with $89 \%$ of those in the pipeline (assistant or associate ADs) also white (Swift, 2011). Results of the present study confirmed that racial barriers exist in regards to the AD position, with $85 \%$ of the sitting Division I ADs identifying as white. Furthermore, aspiring female ADs need to be aware that although the career path of ADs has evolved, it appears that the gender of ADs has not. Men still overwhelmingly hold leadership positions within college sport, as $88.7 \%$ of the ADs in the current study identified as male. Furthermore, despite the fact that female ADs felt that there was a cultural shift occurring within collegiate sport leadership (Taylor \& Wells, 2017), results of this study statistically demonstrate that the "good old boys" network is still very much present within intercollegiate sport. Despite the lack of racial and gender diversity within the AD role, it would be wise to focus on the skills and experiences that ADs perceived to be most important in order to increase the likelihood of securing one of these coveted positions. The ADs suggested getting involved in fundraising early in one's career, building relationships with colleagues on campus and throughout the industry, and securing a mentor. The reality is that one can become an $\mathrm{AD}$ from any area within athletics, but it may take longer to get there at the Division I level without fundraising experience.

Finally, modern ADs work in an environment that is full of constant evolution and innovation. Issues around student-athlete rights and compensation permeate mass media. Coaches' salaries continue to escalate in a manner that might not be sustainable. Furthermore, technological innovation is changing how the athletic department engages with, and reaches, the end consumer. It is crucial that ADs are acutely aware of this dynamic landscape. Future successful ADs will be the ones who demonstrate the ability to be forward-thinking and innovative in their department leadership.

\section{Limitations}

All research studies have limitations. First, the 2015-16 NCAA membership included 1,066 institutions, and the present study only focused on ADs from the 350 Division I institutions, so the 
results may not be generalizable to all ADs. Next, the study relied on a newly created scale to measure the perceptions of which skills and experiences ADs valued. Third, the researcher did not clarify undergraduate or graduate school when soliciting information related to academic majors, so it is unclear when their coursework was taken. The 116 responses was lower than the Cooper and Weight (2011) study with a 43.9\% response rate, but higher than Dittmore et al. (2013) study, which had a $18.3 \%$ response rate. The primary researcher's long tenure in the intercollegiate athletics industry as a practitioner and Senior Associate AD title may have contributed to the response rate. Lastly, this study was practical in nature and as such, lacks a strong theoretical framework that could provide a more convincing justification.

\section{Recommendations for Future Research}

The AD position is extremely sought after and very competitive. Yet, there is very little information available on this population. More accessible information regarding the career paths of ADs could assist those who aspire to be ADs and those hiring ADs. Future research should survey university presidents to compare what they perceive to be most important for ADs with what ADs perceive to be most important to be an effective AD. Additionally, in order to have a better understanding of the perceptions of all ADs in the NCAA, future researchers could continue to survey ADs in Division II and Division III institutions to examine whether ADs in different divisions will have different perceptions in terms of the skills and experiences that are the most important in their positions. Furthermore, future research should not only examine trends and experience among ADs, but also the leadership style of those in this position.

Finally, it would be interesting to look at sport management students and see whether they have interest in becoming an $\mathrm{AD}$. If there is strong interest among sport management students to become a college $\mathrm{AD}$, evaluating the available curriculum may prove beneficial. Based on this study's results, students should be exposed to topics in fundraising and crisis communications, areas that may not be adequately covered in program curricula. While information from this study can assist those with aspirations of becoming an $\mathrm{AD}$, this study can also assist those mentoring students to ensure this population is aware of the experiences required to obtain an $\mathrm{AD}$ position. 


\section{References}

Belzer, J. (2015, February 19). The dynamic role of the modern day college athletics director. Forbes.com. Retrieved from http://www.forbes.com/sites/jasonbelzer/2015/02/19/thedynamic-role-of-the-modern-day-college-athletics-director/\#78dd02922002

Brady, E., Upton, J., \& Berkowitz, S. (2013, March 6). Major college ADs averaging more than $\$ 500,000$ in pay. USAToday.com. Retrieved from http://www.usatoday.com/story/sports/college/2013/03/06/college-athletics-directorssalaries-increase/1964239/

Brassie, P. S. (1989). A student buyer's guide to sport management programs. Journal of Physical Education, Recreation \& Dance, 60(9), 25-29.

Cooper, C. \& Weight, E. (2011). Investigating NCAA administrator values in NCAA Division I athletic departments. Journal of Issues in Intercollegiate Athletics, 4, 74-89.

Dillman, D. A. (2000). Mail and internet surveys: The Tailored Design Method (2nd ed.) New York, NY: John Wiley \& Sons, Inc.

Dittmore, S.W., McCarthy, S.T., McEvoy, C., \& Clavio, G. (2013). Perceived utility of official university twitter accounts: The opinions of college athletic administrators. Journal of Issues in Intercollegiate Athletics, 6, 286-305.

Dittmore, S. W., White, E., Gates, E., Martin, D. C., \& Sanders, C. J. (2011). Predicting career patterns for becoming an NCAA Division I FBS athletic director: Revisiting the "normative" sequence. Abstract presented at the College Sport Research Institute Conference, April 19-22, 2011, Chapel Hill, N.C.

Dosh, K. (2013). Saturday morning millionaires: How winning football builds winning colleges. New York, NY: Turner Publishing Company.

Duderstadt, J. J. (2003). Intercollegiate athletics and the American university: A university president's perspective. Ann Arbor, MI: University of Michigan Press.

Favaro, K., Karlsson, P-O., \& Neilson, G. L. (2010, summer). CEO succession 2000-2009: A decade of convergence and compression. Strategy+Business, 59. Retrieved from 
https://www.strategy-business.com/article/10208

Fitzgerald, M. P., Sagaria, M. A. D., \& Nelson, B. (1994). Career patterns of athletic directors: Challenging the conventional wisdom. Journal of Sport Management, 8, 14-26.

Fram, N., \& Frampton, T. W. (2012). A union of amateurs: A legal blueprint to reshape big-time college athletics. Buffalo Law Review, 60, 1003-1078.

Gruna, A. (2017). How organizing collegiate student-athletes under the National Labor Relations Act with the NCAA as a joint employer can lead to significant changes to the student-athlete compensation rules. Pace Intellectual Property, Sports \& Entertainment Forum. 7, 275-278.

Hardin, R., Cooper, C. G., \& Huffman, L. T. (2013). Moving on up: Division I athletic directors' career progression and involvement. Journal of Applied Sport Management: Research That Matters, 5(3).

Hatfield, B. D., Wrenn, J. P., \& Bretting, M. M. (1987). Comparison of job responsibilities of intercollegiate athletic directors and professional sport general managers. Journal of Sport Management, 1(2), 129-145.

Jones, D. F., Brooks, D.D., \& Mak, J.Y. (2008). Examining sport management programs in the United States. Sport Management Review, 11, 77-91.

Lumpkin, A., Achen, R. M., \& Hyland, S. (2015). Education, experiences, and advancement of athletic directors in NCAA member institutions. Journal of Contemporary Athletics, 9(4), 249-265.

Marburger, D. R. (2015). How are athletic directors rewarded in the NCAA Football Bowl Subdivision? Journal of Sports Economics, 16(3), 254-267.

North American Society for Sport Management. (2016). Academic programs. Retrieved from: http://nassm.org/Programs/AcademicPrograms

Piercy, J. E., \& Forbes, J. B. (1991). The phases of the chief executive's career. Business Horizons, 34(3), 20. 
Quarterman, J. (1992). Characteristics of athletic directors of historically Black colleges and universities. Journal of Sport Management, 6, 52-63.

Salaga, S., \& Fort, R. (2017). Structural change in competitive balance in big-time college football. Review of Industrial Organization, 50, 27-41.

Smith, J., \& Washington, M. (2014). Advancing isomorphism in higher education: A critical analysis of the careers of intercollegiate athletic directors. Journal of Contemporary Athletics, 8, 15 .

Solomon, J. (2014, August 7). NCAA adopts new Division I model giving Power 5 autonomy. CBSsports.com. Retrieved from http://www.cbssports.com/college-football/news/ncaaadopts-new-division-i-model-giving-power-5-autonomy/

Spenard, J. C. (2011). An examination of National Collegiate Athletic Association Division I athletic directors (Master's thesis). Retrieved from http://trace.tennessee.edu/cgi/viewcontent.cgi?article=1003\&context=utk_exerpubs

Suggs, W. (2005). Faces in a mostly white, male crowd. Chronicle of Higher Education, 51(31), A34.

Swift, H. T. (2011). Understanding the career paths and experiences of Division IA athletic directors: A phenomenological study (Doctoral dissertation). Retrieved from ProQuest Dissertations Publishing. 3467815.

Taylor, E. A., \& Wells, J. E. (2017). Institutionalized barriers and supports of female athletic directors: A multilevel perspective. Journal of Intercollegiate Sport, 10(2), 157-183.

Wong, G. M., Deubert, C. R., \& Hayek, J. (2015). NCAA Division I athletic directors: An analysis of the responsibilities, qualifications, and characteristics. Jeffrey S. Moorad Sports Law Journal, 22, 1-73. 